\title{
Research on the Function of French Original Sound Audio in French Classroom Teaching
}

\author{
Li Yang ${ }^{1, \text { a }}$ \\ ${ }^{1}$ College of Liberal Arts, Xi'an International University, Xi'an, Shaanxi, 710077 \\ aemail,
}

Keywords: French; Acoustic Audio Data; French Classroom; Teaching

\begin{abstract}
French acoustic audio material in the French classroom teaching is more widely used can be used as a student language to carry out strong language practice of the main information. French audio has the characteristics of authenticity, the introduction of the French classroom can effectively create a French exchange situation, so that the classroom more interesting, so as to stimulate students' interest in learning to make it better to learn French, to improve the quality of teaching in French classroom purpose. This paper analyzes the role of French acoustic audio data in French classroom teaching, briefly introduces the introduction background of French audio data and the importance of its application, and puts forward some suggestions on how to apply it in French classroom teaching.
\end{abstract}

\section{Introduction}

Most of the French language teaching is an elective course. It is a second foreign language course for students of English majors or other foreign language majors. Compared with the professional French courses, it is a special course that exists in itself and has different audiences and different educational methods. [1]. Professional French students, French teaching is their main classroom, and for students who choose French, French is only their second course, and interest in the higher degree of relevance. University of French students to learn a large number, because it is widely used in many fields, including the field of cars, luxury areas, etc., thus the French teaching methods and teaching materials, material selection is an important factor affecting student learning effect, the introduction of acoustic audio data And the application obtained a good response, this article to discuss this, see below.

\section{Introduction Background of French Soundtrack}

Listening is one of the important channels of foreign language teaching language input, but also has an important influence on students' foreign language learning. Foreign language listening has the characteristics of fleeting and most students in foreign language learning generally believe that the hearing part is difficult to understand. The current international communication is becoming more and more frequent, so the community of many institutions of higher learning students foreign language application ability requirements are gradually improved, English, French is our focus on learning foreign language courses, in addition to France, in many countries in Europe and Africa in many countries in French, but for our students, the choice of French learning in the future development and career planning can be used effectively or unknown factors [2]. French learning and selection is based on student interest and future career considerations, so there is some difference in the quality of learning and quality of the final French language learning. At present, the "teaching requirements of French language courses" is the main basis for judging the learning and effect of French. In this paper, it is one of the teaching strategies to provide students with different levels of French comprehensive utilization ability. The language standard of French is the basic learning part of the future students' learning and development. In order to improve the students' ability of intercultural communication and enhance the students' comprehensive cultural accomplishment, the French audio and video material is introduced in this background. 


\section{The Importance of French Acoustic Audio Applied to French Teaching}

For the professional learning of French students, the French teaching classroom is to carry out the ultimate development of Chinese international, innovative, applied talents as the main teaching objectives, so that students out of the school into the community after a solid foreign language foundation, Understand foreign culture, in international transactions, exchanges, work to play their own value [3]. In the course of teaching, in addition to cultivating its basic skills in France, but also to broaden the students' knowledge of the field of vision, to teach professional knowledge related to France to cultivate its innovative ability and overall quality. So that it can adapt to the French-related foreign affairs, economic, trade, legal, military, educational and other social needs, and can use French as the medium to expand their own professional fields. It can be seen that, for students who specialize in French, the requirements for classroom quality are more stringent, but the students' perceptions of learning are relatively weak. They are not familiar with the language of French. They do not have a higher degree of popularity than English. In the education of teachers are also in a relatively awkward position. In the face of the special requirements of the French teaching in the university, as well as the particularity of the audience and the teachers' groups, the use of the acoustic French audio data effectively alleviates this embarrassment. The teaching begins with the acoustic audio data of the French, combined with the actual learning characteristics of the audience and demand, rich French classroom teaching methods, to a wide range of classroom learning materials for students to create interesting, situational, innovative classroom, and ultimately achieve the French teaching objectives [4].

\section{The Role of French Acoustic Audio in French Teaching}

The Role of the Authenticity of Material. The introduction and application of the French acoustic data has an important role in the teaching of the French classroom. With the existing teaching facilities and equipment as the basis for the integration of the existing information, the introduction of audio and video materials, with vivid and intuitive real material to create a local atmosphere of the learning atmosphere, not only to students to listen, but also allow students to watch the video, in the process of teachers under the guidance of the completion of the various stages of learning tasks. The real phonetic material is the material needed in the French classroom teaching of higher education, the authenticity of the phonetic material has always been the focus of attention of college English teachers [5]. The authenticity of the phonetic material is more applicable to the teaching of French, the application of authenticity material can achieve the following teaching effect: students in the learning process not only master the French learning requirements of the grammar rules, but also through the description of the scene to the target culture To be able to inspire students' interest in learning French. In addition, the French soundtrack material used in the French teaching classroom is selective, and life and development of the material is more practical, can lead to the imagination of students, to increase their understanding of the French language. The application of the authenticity material, despite the traditional teaching methods, simply to listen to practice, but also to achieve good results, material language, vocabulary, voice and so have absolute standards [6]. Therefore, the authenticity of the original audio material in French is applicable to the teaching of French. It is feasible to use the audio and video materials in the daily classroom to enhance the students 'premonition and enhance the students' awareness of the phonetic materials.

The Role of French Scene Creation. Years ago, the American psychologist Pavio made a series of words, picture memory experiments, experimental results show that the same speed to the subjects to give a group of pictures and text information, after the subjects through the memory of the reduction the number of pictures is much more than the number of words. Thus, the memory capacity of the brain for the material is significantly higher than the semantic memory, which in the subsequent education reform process, the educational institutions began to focus on situational teaching, while language and visual effects to convey the information, often able to deepen the memory, this view has been widely recognized by the relevant researchers, which in the classroom professor cannot provide a good real situation, the classroom content is more uniform, lack of 
motivation, thus, the introduction of French audio and sound, books, tape, wall charts, video and other means, allowing students in the classroom in the context of the French, immersive experience of the atmosphere, purposeful learning, subconscious analog communication scene, which the material to understand the deeper content, and even students in life after encountering similar scenes is very easy to recall this scene, and then to achieve the purpose of review.

\section{The Specific Strategy of French Acoustic Audio Applied to French Teaching}

Effective Classroom Integration. Today's technology, information technology developed, the use of the Internet to collect enough French audio data has become simple and feasible. Teachers are concerned about how to use these soundtrack material reasonable, in fact, the application of these materials to the students in line with the current French knowledge structure, in line with the current teaching progress on the basis of its integration in order to achieve the best results. Vivid and rich in the content of the scene easier to construct the meaning of knowledge, so as to achieve better learning results. Learning itself comes from different cultures, knowledge, history, and scientific backgrounds. This background can also be understood as "context". In the context of real life, students can use the experience of the previous cognitive system to perceive new knowledge points, which can deepen students' understanding and memory. It is best to sound audio material into the classroom to carry out the teaching activities, rather than simply as teaching auxiliary information, which can be the original teacher to explain the contact, play an interpretation and complement the role. French audio material has a variety of forms of various situations, including animated short films, monologue, scene dialogue, etc., through the introduction of the material can be more intuitive French classroom teaching statements. Especially video clips, with French dubbing, Chinese and French subtitles, for students to understand the French culture, better learning French provides an important support in the development of new knowledge on the basis of review of the old knowledge.

Situation into the Extension of Teaching. French teaching and English teaching have many similarities, but the popularity of English and a wide range, students learn more simple. The introduction of the French acoustic audio material needs to be well prepared, and after the start of the teaching, the students will be able to understand the meaning of the words in the course of the subsequent viewing of the uncommon words of the relevant material. And in general, video and audio playback time is shorter and you can play a one-time, simplifying the playback process. After the completion of the play, the teacher simply ask questions for the students, a brief summary of the content, so that students answer the material contained in the knowledge points, teachers in the process of answering students in the blackboard, the focus will be listed. Let the students know that the playback process is a learning process, not an episode of entertainment. After the teacher asked questions, so that students with the second question or watch the material, after playing the students to answer the questions raised before, when the students have basically memorized the contents of the material, the answer after the third answer material, and then let the students grouped to imitate the recurrence of the situation, and according to their previous learning knowledge to play freely, to join their own point of view, set up dialogue, mutual exchange, very good to do the extension of teaching. Material three times each time there are different problems into the point, this process students into the situation very well, greatly stimulated the students interest in learning, after three times should not play again, then play will appear monotonous boring, lost the original meaning, will also reduce the nature of the students.

\section{Conclusion}

In summary, the French acoustic audio material with its unique characteristics of the Chinese institutions of higher education in France had a great impact. In recent years, Chinese major colleges and universities gradually implemented the upsurge of Sino-foreign cooperation in running schools, so that the French language teaching in the institutions of higher learning has a new requirement for acoustic audio material, and its recognition has reached a new height. Through this 
research and analysis, it is difficult to see the applicability of French audio material in French teaching in colleges and universities, which is in full accord with the demand of French classroom teaching. Therefore, based on the full consideration of the emotional factors of French learners, it is integrated into the classroom, in the real context to achieve the desired goal of teaching.

\section{References}

[1] Sun Peijian. A Comparative Study of Second Language Classroom Teaching Strategies in Non-target Language Context - A Case Study of Chinese, French and German Teaching in Oklahoma University [J]. Language Teaching and Research, 2013,04: 8 -16.

[2] Pan laugh. Open the golden key of the French classroom treasury gate - play the main role of students in French classroom teaching [J]. Science and Technology Guide (late), 2016,03: 105-106.

[3] Yao Hong, Gao Qin. "Internet +" era of flip classroom and two foreign language teaching research - new opportunities, new changes [J]. Modern communication, 2016,12: 205-206.

[4] Li Na, Wei Lu Xiao. French acoustic audio data in the classroom teaching application [J]. Journal weekly, 2013, 34: 10-11.

[5] Zhang Ge, Wang Mingli.Application of TV News as Real Input Corpus in French Listening Classroom [J]. Modern Communication (Journal of Communication University of China), 2014,04: 137-141.

[6] Wang Jie. Explore two new ways of French teaching in foreign languages - Let students master classroom discourse rights [J]. Journal of Jiamusi Vocational College, 2015, 04: 213-214. 